\title{
The Relationship Between the Pneumatization Patterns of the Frontal Sinus, Crista Galli and Nasal Septum: A Tomography Study
}

\author{
Gulay ACAR ${ }^{1}$, Aynur Emine CICEKCIBASI ${ }^{1}$, Mustafa KOPLAY², Kazım Serhan KELESOGLU²
}

${ }^{1}$ Necmettin Erbakan University, Meram Faculty of Medicine, Department of Anatomy, Konya, Turkey

${ }^{2}$ Selcuk University, Faculty of Medicine, Department of Radiology, Konya, Turkey

This study has been presented at the $1^{\text {st }}$ International Congress on Sports, Anthropology, Nutrition, Anatomy and Radiology between 3 and 5 May 2018 at Nevsehir, Turkey.

Corresponding author: Gulay ACAR gulayzeynep73@gmail.com

\section{ABSTRACT}

AIM: To provide detailed information about anterior skull base anatomy.

MATERIAL and METHODS: In terms of gender and laterality, the drainage pathways and anatomical variations of the frontal sinus, crista galli and nasal septum in 402 patients were evaluated via computed tomography scans.

RESULTS: The pneumatization patterns of the frontal sinus were as follows: absent, 3.7\%; unilateral, $8 \%$; bilateral, $75.1 \%$ and triple, $13.2 \%$. The pneumatized crista galli was identified in $120(29.8 \%)$ patients, and its drainage pathway was observed in $54.1 \%$ of patients. The sinus septi nasi was identified in 92 (22.8\%) and its drainage pathway was observed in 16.3\%. The prevalences of the position types of crista galli regarding the cribriform plate were as follows; type I, 18.3\%; type II, $64.9 \%$; type III, $16.8 \%$.

CONCLUSION: Despite meticulous knowledge of anatomy, preoperative radiologic evaluation creates the base for successful treatment of anterior skull base pathologies with safer and effective surgery.

KEYWORDS: Anterior skull base anatomy, Computed tomography, Crista galli, Frontal sinus, Sinus septi nasi

\section{INTRODUCTION}

$\mathrm{T}$ The frontal sinus (FS) and the less common types of extrasinusal pneumatizations including the crista galli (CG) and nasal septum (NS), are in close localisation and communicate with each other if pneumatization occurs. These neighbouring structures are critical landmarks during anterior skull base surgery and endoscopic sinus surgery (ESS) $(12,13)$. Computed tomography (CT) scan provides extremely good opportunities for the evaluation of these bony structures. The relationship between the pneumatization patterns of these structures and the anatomical variation of the drainage pathways is extremely important in obtaining a differential diagnosis and in performing surgery for benign lesions in the anterior skull base and cerebrospinal fluid (CSF) leak $(13,17)$. The FS is a nascent pneumatization in the fourth or fifth week of gestation and reaches its final size at the age of 20 years. The pneumatic cavities in the FS are separated with complete intersinus septum or fused and also, one or both sinuses may be absent. The fused middle sinus can be prominently observed as an attachment of both sinuses. As the FS of each individual is unique, even in monozygotic twins, it can facilitate a precise and detailed analysis of personal identification $(21,25)$.

The CG, which limits the olfactory fossa medially and projects on the midline of the cribriform plate, superiorly originates from the ethmoid bone during foetal period and turns into a
Gulay ACAR (D) : 0000-0002-9524-5056

Aynur Emine CICEKCIBASI (D) : 0000-0002-1373-3065
Mustafa KOPLAY

(D) : 0000-0001-7513-4968

Kazım Serhan KELESOGLU (D) : 0000-0001-6745-6828 
compact or spongy bone $(8,16)$. However, the main inferences based on radiological anatomy studies were the fact that $2.4 \%-37.5 \%$ of the pneumatized CG, also referred to as the sinus crista galli (SCG), mostly drains into the FS or ethmoid sinus. The drainage pathway of the $C G$ can play a role in disseminating of frontal pathologies into the CG $(9,10,13)$. In clinical settings, nasal dermoids, congenital midline nasal defects, mucocele and iatrogenic CSF leak can be associated with the SCG. In addition to the drainage pathway of the CG, the position types of the $\mathrm{CG}$ with respect to the cribriform plate, which is an extremely important morphologic barrier in anterior skull base surgery, must be identified $(8,11,17)$. The pneumatized NS which is referred to as the sinus septi nasi (SSN), is caused by the extension of the sphenoid sinus or the FS and also, the vomeronasal organ. CT scan of the SSN has potential implications on surgical treatment planning and obtaining an accurate diagnosis of inflammation (12).

Based on such data, the anatomical variability in these pneumatized structures is crucial for understanding the pathophysiology and complications of diseases and, it should be considered during anterior skull base surgeries $(11,25)$. The present study aimed to identify the normal pneumatization patterns of the FS and its adjacent structures (the CG and NS) and the relationships between them. Knowledge of these normal anatomical variations is essential in increasing the success rate of safe and effective surgeries without iatrogenic complications.

\section{MATERIAL and METHODS}

The local ethics committee approved the present study (Approval Number: 2018/1209), and the facial CT images of 402 patients, aged 20-81 years, who presented at the department of radiology between January 2018 and May 2018 were used in this study. Patients who had bone fractures, congenital craniofacial anomaly and pathologies, perforations in the paranasal sinuses and those with damaged the bony contours due to surgeries were excluded.

All patients were evaluated using a 128-slice multidetector CT scanner (Siemens, SOMATOM Flash) with the following parameters: 0.625 collimation, $120 \mathrm{kV}, 160 \mathrm{~mA}$ and $220 \mathrm{~mm}$ FOV. Using the Syngovia (Siemens) Workstation software, the images were reconstructed based on the axial images obtained with a section thickening of $0.625 \mathrm{~mm}$, and the variations were then analysed. To prevent visual tiredness, a maximum of 10 images per day was evaluated. To minimise interobserver error and ensure accuracy, one anatomist and one radiologist carried out all measurements and observation of the variations.

The sinus images were examined in all planes, and the metric variables were measured using the point where the diameter of the sinus was largest. The dimension values of the FS, which include width (between lateral margins), height (from superior to inferior margins) (Figures $1 A-C, 2 A)$ and length (from anterior to posterior margins) (Figure 2B) were measured. According to the presence of complete intersinus septum (dividing the sinus cavity into two cells), the pneumatisation patterns of the FS were classified as follows: absent, unilateral presence, bilateral presence (one septum) and triple (two septums) (Figures 1A-C, 2A). In addition, we determined the number of partial septum, which is a line $\geq 1 \mathrm{~mm}$ extending from the bony border of the cavity into the sinus space (not completely dividing the cavity) and scalloped arcade (diversity of continuity of the bony border as inward and outward cavity arcs) (Figures 1A-C).

We observed the pneumatized CG in the sagittal and coronal planes (Figures $3 \mathrm{~A}-\mathrm{C}$ ), and detected the drainage pathway of the SCG into the adjacent sinuses in the axial planes (Figures $4 A-C)$. The pneumatized NS and the drainage pathway of the SSN were identified in the coronal planes (Figures $5 A-C$ ). In addition, we measured the SCG and SSN volumes in the coronal plane. Using the available region-of-interest (ROI) tool vailable in the Syngovia software, the SCG and SSN volumes were measured manually by marking the lumen (space within the bony walls) of the sinus in each of the coronal plane slices. The same observers automatically calculated the total volume of each slices of the sinus using the software.

The positions of the CG were also assessed using the classification of Hajiioannou et al. based on the relationship with the cribriform plate and were categorized into three types (8):

Type I - the base of the CG was located at the level of the cribriform plate (Figure 6A).


Figure 1: Pneumatization patterns, partial septum (arrow head), scalloped arcade (thick arrow), intersinus septum (thin arrow), the widths (dashed line) and the heights of frontal sinuses (straight line) were shown in coronal plane. A, B) Three and two dimensionally reconstructed images of triple frontal sinus; C) bilateral presence. 
Type II - $<50 \%$ of the height of the CG was located below the level of the cribriform plate (Figure 6B).

Type III - $>50 \%$ of the height of the CG was located below the level of the cribriform plate (Figure 6C).

\section{Statistical Analysis}

Statistical analyses were performed using the Statistical Package for the Social Sciences software version 22 (SPSS,
Inc., Chicago, IL, the USA), and the Mann-Whitney $U$ test, paired and unpaired $t$ tests were used to evaluate the relationships of the values that can be measured between the groups. For the statistical comparisons of the prevalence of the pneumatization descriptive statistics, chi-square test and one-way analysis of variance (ANOVA) were used. A $p$ value $<0.05$ was considered significant.
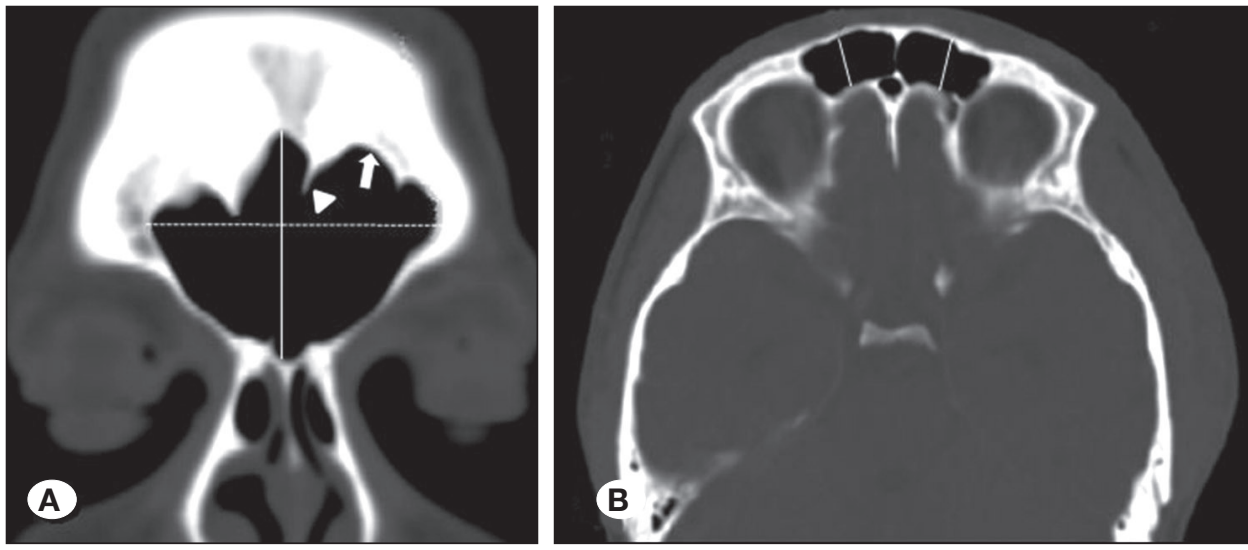

Figure 2: A) A partial septum (arrow head), scalloped arcade (thick arrow), width (dashed line) and height (straight line) of the fused (unilateral presence) frontal sinus in coronal plane; $B$ ) the measurement of right length (RL) and left length (LL) of frontal sinus in axial plane.
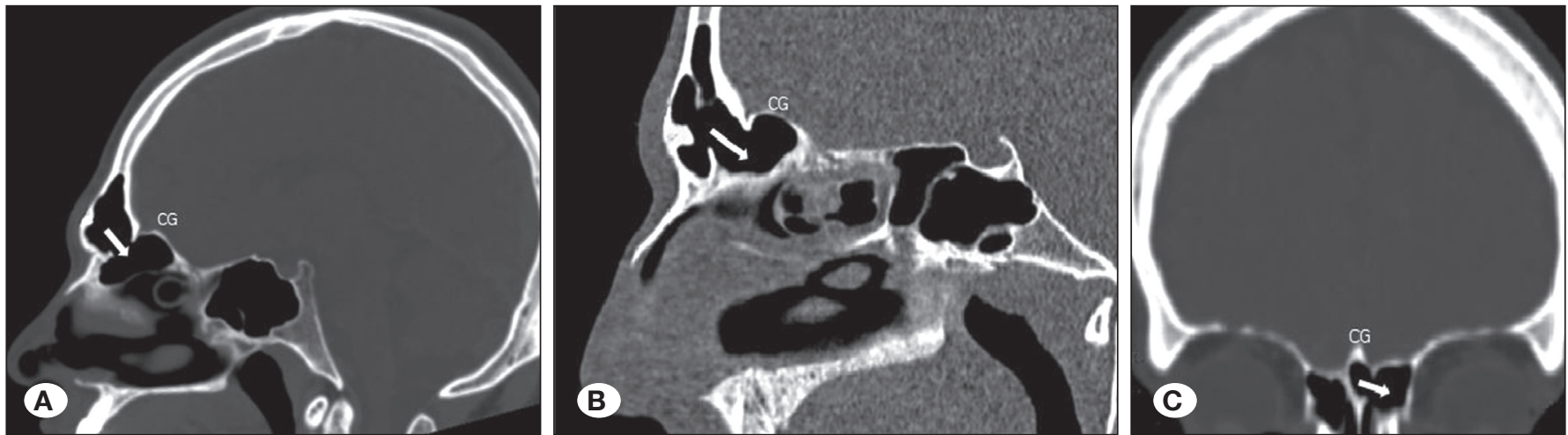

Figure 3: A, B) The pneumatized crista galli (CG) as a compartment of frontal sinus in sagittal plane, C) CG was pneumatized from left ethmoid sinus in coronal plane. Thick arrows show a drainage pathway.
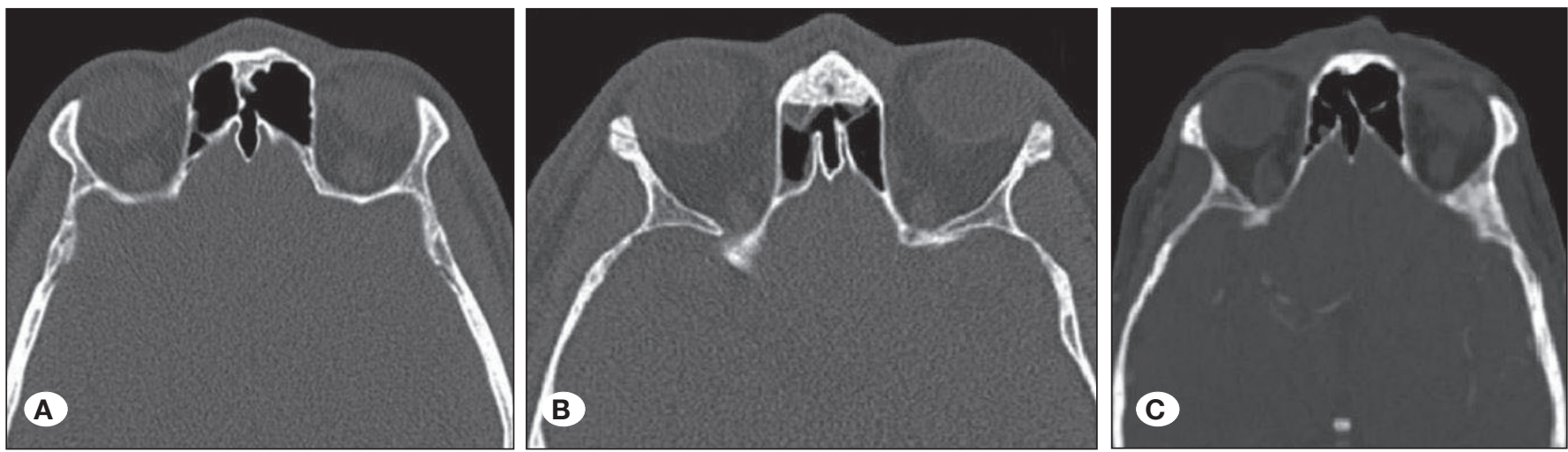

Figure 4: A drainage pathways of sinus crista galli in axial planes. A) Sinus crista galli in communication with left frontal sinus, B) sinus crista galli as a compartment of right frontal sinus, C) sinus crista galli in communication with right ethmoid sinus. 

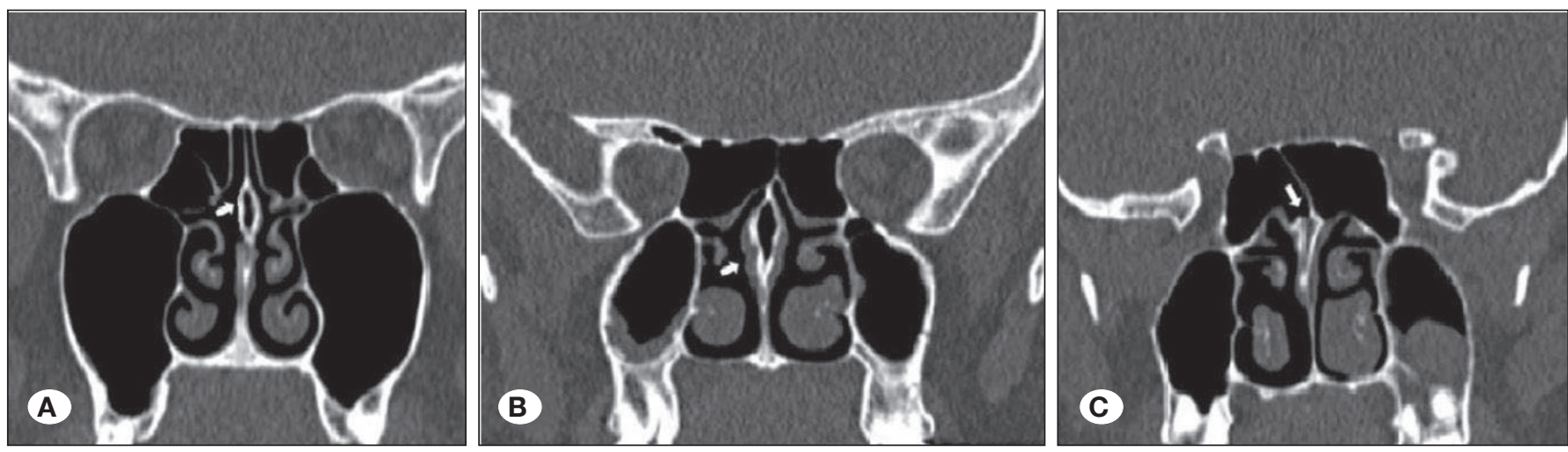

Figure 5: The pneumatized nasal septums (thick arrow) in coronal planes. A, B) Sinus septi nasi located at the lamina perpendicularis of ethmoid bone, C) sinus septi nasi in communication with right sphenoid sinus.
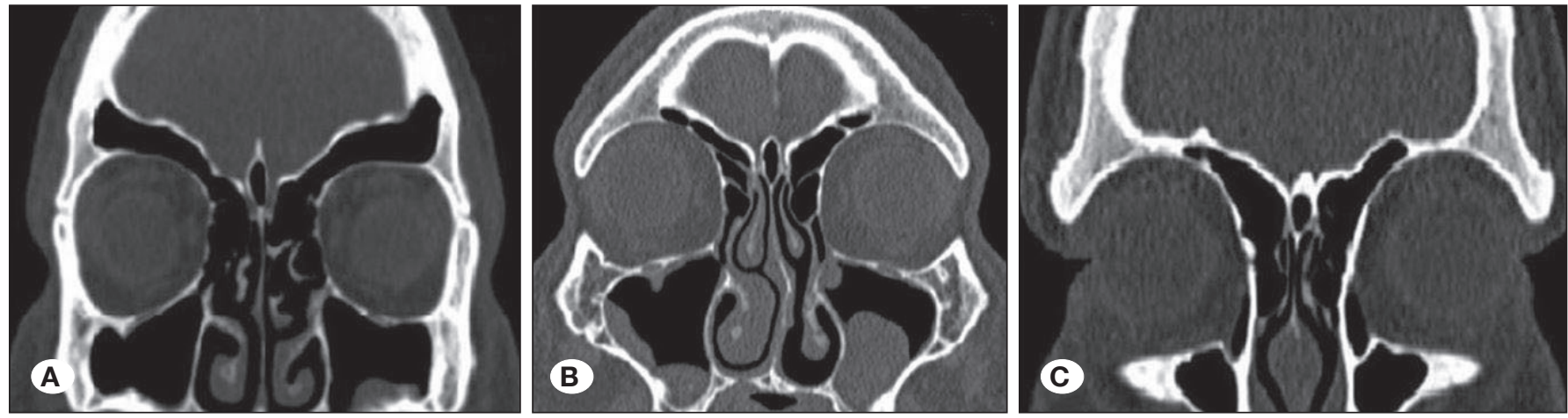

Figure 6: The positions of the pneumatized crista galli base in relation to the cribriform plate. A) Type l; at the level of the cribriform plate, B) Type II; $<50 \%$ of the crista galli is below the level, C) Type III; $>50 \%$ of the crista galli is located below the level.

\section{RESULTS}

Among the participants, 195 (48.5\%) were females (median age: $43.84 \pm 16.85$ years) and $207(51.5 \%)$ were males (median age: $39.21 \pm 15.55$ years).

\section{FS Morphometry and Variations}

The distribution of pneumatization patterns and variations of the FS were shown in Table I. In 15 (3.7\%) of the patients (11 female, 4 male), the FS was not observed; thus, it was not included in the morphometric measurements. The unilateral presence of the FS (7 right, 7 fused middle and 18 left) was observed in 32 (8\%) patients (16 female, 16 male). The FS was separated by one complete intersinus septum (bilateral presence of the FS) in 302 (75.1\%) patients and by two (triple FS) in $53(13.2 \%)$ patients. Moreover, no significant differences were observed in the prevalence in terms of sex, laterality and age, except for the bilateral absence of the FS. Furthermore, both the prevalence of the presence of the FS and the number of partial septum (0-4) and scalloped arcades (0-5) in the FS were significantly higher in males as compared to females (Table I, $\mathrm{p}<0.05$ ).

The width, height and length of the FS were 4.3-55.1 mm, 3.9-49.9 $\mathrm{mm}$ and $1.8-25 \mathrm{~mm}$, respectively. The comparisons in all the dimension values of the FS in terms of sex and laterality were shown in Tables II and III. All mean values were higher in males than females and showed statistically significant differences $(p<0.05)$. By contrast, in terms of unilateral presence patterns, the mean dimension values of the FS were significantly higher in the fused middle than in the right or left $(p<0.001)$. In addition, the dimension values of the FS were higher in the left than in the right. However, the difference was not statistically significant $(p>0.05)$. Inter and intraobserver reliability was equal to or higher than $85 \%$ for all measurements. In case of a different value $(>0.1 \mathrm{~mm})$, disagreement between observers was resolved via discussion and consensus or using the recorded average.

\section{Morphometry and Variations in the SCG and SSN}

The pneumatized CG was observed in 120 (29.8\%) patients (59 female, 61 male), and the pneumatized NS was identified in 92 (22.8\%) patients (50 female, 42 male), respectively (Table I). The drainage pathways of the SCG were identified in 65 (54.1\%) of 120 patients which were as follows: 49 connected to the FS (28 right, 21 left) and 8 connected to the ethmoid sinus. Moreover, eight SCGs were observed as a compartment of the FS. In 92 SSN, communication with the sphenoid sinus was observed in 15 (16.3\%) patients. The prevalence of SCG and SSN did not significantly differ in terms of sex and age. The mean SCG and SSN volumes were $15.42 \pm 6.13$ and $12.66 \pm$ $7.04 \mathrm{~mm}^{3}$ in females, and $18.52 \pm 7.59$ and $13.19 \pm 7.57 \mathrm{~mm}^{3}$ 
Acar G. et al: Frontal Sinus, Crista Galli and Nasal Septum

Table I: Distribution of Pneumatization Patterns and Variations of the Frontal Sinus and Ethmoid Structures

\begin{tabular}{|c|c|c|c|c|c|c|}
\hline \multirow{2}{*}{$\begin{array}{l}\text { Pneumatization patterns and } \\
\text { variations of the frontal sinus }\end{array}$} & \multicolumn{2}{|c|}{$\begin{array}{l}\text { Female } \\
(n=195)\end{array}$} & \multicolumn{2}{|c|}{$\begin{array}{c}\text { Male } \\
(\mathrm{n}=207)\end{array}$} & \multicolumn{2}{|c|}{$\begin{array}{c}\text { Total } \\
(\mathrm{n}=402)\end{array}$} \\
\hline & $\mathbf{n}$ & $\%$ & $\mathbf{n}$ & $\%$ & $\mathbf{n}$ & $\%$ \\
\hline Partial septum & 37 & $19(37 / 195)$ & 67 & $32^{\star \star}(67 / 207)$ & 104 & $25.9 \%(67 / 207)$ \\
\hline Scalloped arcades & 74 & $37.9(74 / 195)$ & 104 & $50.2^{\star}(104 / 207)$ & 178 & $32 \%(178 / 207)$ \\
\hline \multicolumn{7}{|c|}{ Frontal Sinus Pneumatization Patterns } \\
\hline Bilateral absence & 11 & 5.7 & 4 & $1.9^{\star *}$ & 15 & 3.7 \\
\hline Unilateral presence & 16 & 8.2 & 16 & 7.7 & 32 & 8 \\
\hline Bilateral presence & 142 & 72.8 & 160 & 77.3 & 302 & 75.1 \\
\hline Triple frontal sinus & 26 & 13.3 & 27 & 13.1 & 53 & 13.2 \\
\hline \multicolumn{7}{|c|}{ The prevalences of pneumatized ethmoid structures } \\
\hline Sinus Crista Galli & 59 & 30.3 & 61 & 29.5 & 120 & 29.8 \\
\hline Sinus Septi Nasi & 50 & 25.6 & 42 & 20.3 & 92 & 22.8 \\
\hline Drainage pathways & \multicolumn{2}{|c|}{ Frontal sinus } & \multicolumn{2}{|c|}{ Ethmoid sinus } & \multicolumn{2}{|c|}{ Sphenoid sinus } \\
\hline Sinus Crista Galli $(65 / 120)$ & 57 & 87.7 & 8 & 12.3 & & \\
\hline Sinus Septi Nasi (15/92) & & & & & 15 & 16.3 \\
\hline
\end{tabular}

Chi-square test. ${ }^{*} p<0.05,{ }^{*} p<0.001$.

Table II: The Comparison in Measurement Values of Frontal Sinus Between Females and Males

\begin{tabular}{|c|c|c|c|}
\hline \multirow{2}{*}{$\begin{array}{l}\text { Morphometric } \\
\text { measurements }\end{array}$} & Female & Male & Total \\
\hline & Mean \pm SD & Mean \pm SD & Mean \pm SD \\
\hline \multicolumn{4}{|c|}{ Unilateral presence of frontal sinus (16 female, 16 male) } \\
\hline FSW (mm) & $20.7 \pm 10.9$ & $28.5 \pm 15^{*}$ & $24.3 \pm 13.4$ \\
\hline $\mathrm{FSH}(\mathrm{mm})$ & $15.1 \pm 8.8$ & $21.6 \pm 10.3^{*}$ & $18.1 \pm 9.9$ \\
\hline $\mathrm{FSL}(\mathrm{mm})$ & $8.2 \pm 2.6$ & $11.3 \pm 3.4^{*}$ & $9.6 \pm 3.3$ \\
\hline \multicolumn{4}{|c|}{ Bilateral presence of frontal sinus } \\
\hline FSW (mm) & $22.4 \pm 7.1$ & $25.6 \pm 8.0$ * & $24.1 \pm 7.7$ \\
\hline $\mathrm{FSH}(\mathrm{mm})$ & $20.4 \pm 8.8$ & $26.1 \pm 9.3^{*}$ & $23.4 \pm 9.0$ \\
\hline $\mathrm{FSL}(\mathrm{mm})$ & $9.4 \pm 3.2$ & $12.1 \pm 3.8^{*}$ & $10.8 \pm 3.6$ \\
\hline \multicolumn{4}{|l|}{ Triple frontal sinus } \\
\hline FSW (mm) & $14.7 \pm 6.9$ & $18.4 \pm 8.1^{*}$ & $16.5 \pm 7.8$ \\
\hline $\mathrm{FSH}(\mathrm{mm})$ & $16.7 \pm 7.1$ & $24.0 \pm 9.9$ * & $20.3 \pm 8.3$ \\
\hline FSL (mm) & $8.8 \pm 2.9$ & $11.3 \pm 4.6$ * & $10.0 \pm 4.0$ \\
\hline
\end{tabular}

FSW: Frontal sinus width, FSH: Frontal sinus height, FSL: Frontal sinus length. Mean \pm standard deviation. Unpaired $t$-test. ${ }^{*} p<0.05$.

in males, respectively (Table IV). The mean volume of the SCG did not significantly differ in terms of $\operatorname{sex}(p=0.015)$.

In Table V, the distributions of the 402 CG types (localisation with respect to the cribriform plate) were classified as follows: type I, 18.3\% (74/402); type II, 64.9\% (261/402) and type III,
$16.8 \%$ (67/402). The prevalence rates did not significantly differ in terms of sex and age. The prevalence rates of the pneumatization incidence in the CG types were as follows: $37.8 \%$ (28/74) in type I (14 male, 14 female), 31.4\% (82/261) in type II (40 male, 42 female) and 14.9\% (10/67) in type III (4 
male, 6 female). Thus, the SCG was mostly observed in type $\mathrm{I}$ and II, as summarised in Table VI $(\mathrm{p}<0.05)$. Moreover, the results for the number of SCG were as follows: $14(29.8 \%)$ in the bilateral and unilateral absence of the FS $(n=47), 88(29.1 \%)$ in the bilateral presence of the FS $(n=302)$ and $18(33.9 \%)$ in triple FS ( $n=53)$. Thus, no relationship was observed between the pneumatization patterns of the FS and the incidence of SCG.

Table III: The Distribution of Morphometric Measurement Values with Respect to Laterality

\begin{tabular}{|c|c|c|c|}
\hline \multirow{2}{*}{$\begin{array}{l}\text { Morphometric } \\
\text { measurements }\end{array}$} & Right & Middle & Left \\
\hline & Mean \pm SD & Mean \pm SD & Mean \pm SD \\
\hline \multicolumn{4}{|c|}{ Unilateral presence of frontal sinus (7 right, 7 middle, 18 left) } \\
\hline $\mathrm{FSW}(\mathrm{mm})$ & $19.6 \pm 10.6$ & $43.1 \pm 9.7^{*}$ & $18.9 \pm 8.2$ \\
\hline $\mathrm{FSH}(\mathrm{mm})$ & $12.4 \pm 6.2$ & $31.5 \pm 10.1^{*}$ & $15.2 \pm 5.9$ \\
\hline $\mathrm{FSL}(\mathrm{mm})$ & $8.8 \pm 3.5$ & $12.5 \pm 3.2^{*}$ & $8.8 \pm 2.8$ \\
\hline \multicolumn{4}{|c|}{ Bilateral presence of frontal sinus } \\
\hline $\mathrm{FSW}(\mathrm{mm})$ & $23.4 \pm 7.5$ & & $24.7 \pm 8.0$ \\
\hline $\mathrm{FSH}(\mathrm{mm})$ & $22.9 \pm 8.7$ & & $23.9 \pm 9.3$ \\
\hline $\mathrm{FSL}(\mathrm{mm})$ & $10.6 \pm 3.6$ & & $11.1 \pm 3.6$ \\
\hline \multicolumn{4}{|l|}{ Triple frontal sinus } \\
\hline $\mathrm{FSW}(\mathrm{mm})$ & $16.7 \pm 7.8$ & $13.3 \pm 6.0$ & $19.6 \pm 8.1$ \\
\hline $\mathrm{FSH}(\mathrm{mm})$ & $17.5 \pm 7.5$ & $22.1 \pm 9.0$ & $21.2 \pm 9.7$ \\
\hline $\mathrm{FSL}(\mathrm{mm})$ & $10.1 \pm 3.9$ & $9.9 \pm 4.0$ & $10 \pm 4.2$ \\
\hline
\end{tabular}

FSW: Frontal sinus width, FSH: Frontal sinus height, FSL: Frontal sinus length. Mean \pm standard deviation. Paired t-test. ${ }^{*} p<0.001$.

Table IV: The Distribution of the Comparison in Measurement Values Between Females and Males

\begin{tabular}{ccccc}
\hline & Female & Male & Total & p value \\
\cline { 2 - 4 } Measurements & Mean \pm SD & Mean \pm SD & Mean \pm SD & \\
\hline SCGV $\left(\mathrm{mm}^{3}\right)$ & $15.42 \pm 6.13$ & $18.52 \pm 7.59$ & $17.0 \pm 7.06$ & $\mathbf{0 . 0 1 5}$ \\
\hline SSNV $\left(\mathrm{mm}^{3}\right)$ & $12.66 \pm 7.04$ & $13.19 \pm 7.57$ & $12.9 \pm 7.05$ & 0.730 \\
\hline
\end{tabular}

SCGV: Sinus Crista Galli volume, SSNV: Sinus Septi Nasi volume. Mean \pm standard deviation. Unpaired t-test.

Table V: The Distribution of the Crista Galli Base in Relation to the Cribriform Plate in Different Studies

\begin{tabular}{|c|c|c|c|c|c|c|c|}
\hline \multirow{3}{*}{ Studies } & \multirow{3}{*}{$\begin{array}{l}\text { Imaging } \\
\text { Modality, n }\end{array}$} & \multicolumn{6}{|c|}{ Crista Galli Types } \\
\hline & & \multicolumn{2}{|c|}{ Type I } & \multicolumn{2}{|c|}{ Type II } & \multicolumn{2}{|c|}{ Type III } \\
\hline & & $\mathbf{n}$ & $\%$ & $\mathbf{n}$ & $\%$ & $\mathbf{n}$ & $\%$ \\
\hline Hajiioannou et al., 2010 (8) & CT, 99 & 28 & 28.3 & 63 & 63.6 & 8 & 8.1 \\
\hline Kim et al., 2012 (9) & CT, 818 & 114 & 13.9 & 689 & 84.2 & 15 & 1.8 \\
\hline Poje et al., 2014 (16) & CT, 527 & 119 & 22.6 & 298 & 56.4 & 110 & 20.9 \\
\hline Cobzeanu et al., 2014 (4) & CT, 205 & 48 & 23.41 & 127 & 61.65 & 30 & 14.64 \\
\hline Mladina et al., 2017 (13) & Skull CBCT, 102 & 31 & 45.58 & 37 & 54.42 & & \\
\hline Present Study, 2018 & CT, 402 & 74 & 18.3 & 261 & 64.9 & 67 & 16.8 \\
\hline
\end{tabular}

Type I: Base of the crista galli is located at the level of the cribriform plate, Type II: Less than $50 \%$ of the height of the crista galli is located below the level of the cribriform plate, Type III: More than $50 \%$ of the height of the crista galli is located below the level of the cribriform plate. 


\section{DISCUSSION}

Benign lesions in the anterior skull base include olfactory groove or FS meningiomas, and such lesions can cause neurological symptoms by applying pressure on adjacent neurovascular structures. Olfactory groove meningiomas arise from the dura of the cribriform plate or frontosphenoid suture, and the relationship between the SCG and neurovascular structures entering via the small cribroethmoidal foramina is associated with a higher risk of iatrogenic cerebrospinal fluid leak or mucocele formation. The anatomic and radiologic knowledge about the structure of the anterior skull base is extremely important in surgeries such as; bifrontal craniotomy and endoscopic surgery based on the choice of the surgeon and the size of the tumour $(1,13)$. In addition, the pathologic invasion of the SCG and SSN can result in loss of vision or olfaction; thus, surgical resection may be required $(12,13)$. The variations in the normal bony anatomy in the anterior skull base and the drainage pathway of extrasinusal ethmoid structures can be easily detected on CT scans via multiplanar reconstruction. The radiological evaluation of these pneumatized bony structures aim to provide an objective assessment

Table VI: The Prevalence of Sinus Crista Galliin Crista Galli Types and Pneumatization Patterns of Frontal Sinus

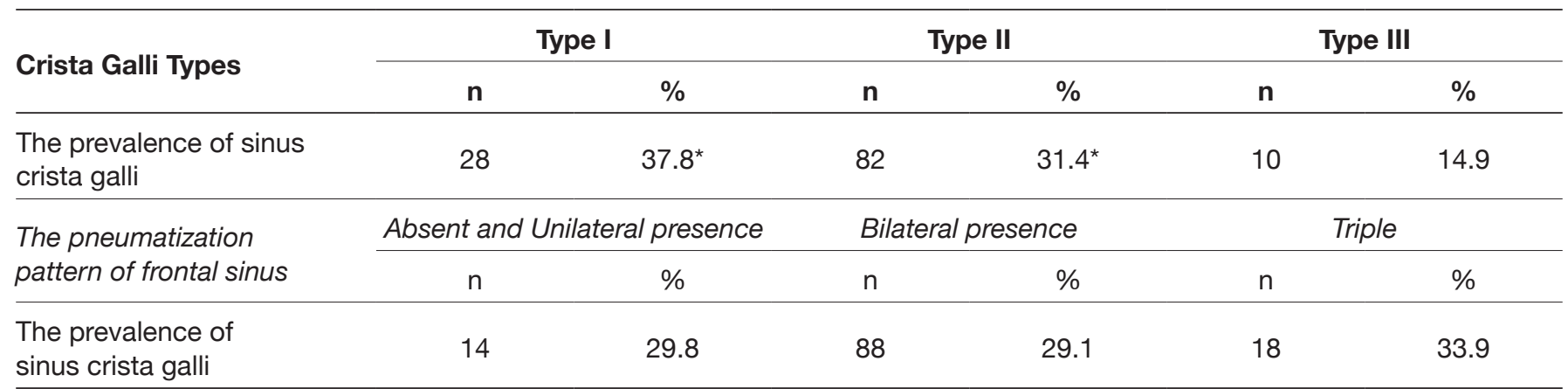

Type I: base of the crista galli is located at the level of the cribriform plate, Type II: less than $50 \%$ of the height of the crista galli is located below the level of the cribriform plate, Type III: more than $50 \%$ of the height of the crista galli is located below the level of the cribriform plate. One-Way Analysis of Variance (ANOVA) test. ${ }^{*} p<0.05$.

Table VII: The Distribution of the Prevalences of Pneumatization Patterns of the Frontal Sinus, Crista Galli and Nasal Septum in Different Studies

\begin{tabular}{|c|c|c|c|c|c|}
\hline \multirow{2}{*}{ Studies } & \multirow{2}{*}{$\begin{array}{l}\text { Imaging } \\
\text { Modality, n }\end{array}$} & \multicolumn{2}{|c|}{ Bilateral absence } & \multicolumn{2}{|c|}{ Unilateral presence } \\
\hline & & $\mathrm{n}$ & $\%$ & $\mathrm{n}$ & $\%$ \\
\hline Tatlisumak et al. 2008 (21) & $\mathrm{CT}, 300$ & 0 & 0 & 4 & 1.33 \\
\hline Danesh-Sani et al. 2011 (5) & CT, 565 & 47 & 8.3 & 63 & 5.6 \\
\hline Gotlib et al. 2015 (7) & CT, 305 & 40 & 1.3 & 40 & 6.5 \\
\hline Nikam et al. 2015 (14) & PA graphy, 109 & 6 & 5.5 & 3 & 2.75 \\
\hline Soman et al. 2016 (19) & СВСТ, 200 & 13 & 6.5 & 6 & 3 \\
\hline Yuksel Aslier et al. 2016 (25) & skull CT, 74 & 3 & 4.1 & 0 & 0 \\
\hline \multirow[t]{2}{*}{ Present study 2018} & CT, 402 & 15 & 3.7 & 32 & 4 \\
\hline & & \multicolumn{2}{|c|}{ Pneumatized crista galli } & \multicolumn{2}{|c|}{ Pneumatized nasal septum } \\
\hline Som et al. 2009 (18) & CT, 200 & 26 & 13 & & \\
\hline Hajiioannou et al. 2010 (8) & CT, 99 & 10 & 10.1 & & \\
\hline Poje et al. 2014 (16) & CT, 527 & 198 & 37.5 & & \\
\hline Manea and Mladina 2016 (10) & CT, 196 & 59 & 30.1 & & \\
\hline Odat and Al-Qudah 2016 (15) & CT, 65 & 56 & 86 & 41 & 63 \\
\hline Mladina et al. 2017 (12) & skull CT, 93 & & & 30 & 32 \\
\hline Present study 2018 & CT, 402 & 120 & 29.8 & 92 & 22.8 \\
\hline
\end{tabular}


of the anterior skull base anatomy and to improve the safety profile of the surgery by analysing the relationship between the pneumatization patterns and drainage pathways that may be essential in the differential diagnosis of sinonasal pathologies and tumours localised in this region $(6,17,23)$.

In the literature, Tatlisumak et al. have categorised the anatomic variations of the FS according to the number of scalloping arcade, complete or partial septum and pneumatization patterns. Meanwhile, Yuksel Aslier et al. have used CT-based volumetry for classification $(21,25)$. In light of clinical studies, a large hyperpneumatized FS can significantly cause prolonged headaches, whereas aplasia or hypoplasia, which is observed in approximately $15 \%$ of the population, can result in chronic allergic rhinosinusitis $(3,22)$. Yu et al. reported that the volume of the frontal sinuses was $33 \%$ lower in patients with contusion than in those without, thereby supporting the theory showing that the FS has protective effects against frontal brain contusion (24). We observed the pneumatization patterns of the FS, which were as follows: absent (15/402, $3.7 \%)$, unilateral presence $(32 / 402,8 \%)$, bilateral presence (302/402, 75.1\%) and triple FS (53/402, 13.2\%). However, no significant difference was observed in terms of sex, except for the bilateral absence of the FS which was more commonly observed in female than male (Table I). As shown in Table VII, different authors have reported about the varying prevalence rates of the bilateral absence and unilateral presence of the FS, which range from $0 \%$ to $8.3 \%$, and a close correlation was observed based on the results of our study $(5,7,14,19,21,25)$.

According to the literature, the FS width ranges from 18 to $31.2 \mathrm{~mm}$; height from 23.6 to $31.7 \mathrm{~mm}$; and sinus length from 10.2 to $21.9 \mathrm{~mm}(14,19,21,25)$. In our study, the mean width, height and length values for FS were 23.1 \pm 9.1, $20.4 \pm 8.4$ and $10.0 \pm 3.7 \mathrm{~mm}$, respectively. All the mean values of the dimensions of the FS were higher in males than females and statistically significant differences were observed (Table II, $\mathrm{p}<0.05$ ). The FS dimensions were larger on the left side (Table III), which is similar to that of some other studies. However, no significant differences were observed $(19,21,25)$. In addition, the mean dimension values of the unilateral presence of the FS were largest in the fused middle, and statistically significant differences were observed $(p<0.001)$. In addition, the number of partial septum and scalloped arcade of the FS in the present study were significantly higher in males as compared to females (Table I). However, some authors did not found significant association between them $(14,19,21)$.

In previous studies, the prevalence rate of iatrogenic CSF leak is $16 \%$ in anterior skull base surgeries, which include the cribriform plate of the ethmoid bone (80\%), FS (8\%) and sphenoid sinus (4\%). Due to the firm adherence to the dura in these regions, the anatomical variations of the pneumatized bony structures can cause CSF leak. In particular, the attachments of the CG to the falx cerebri and superior sagittal sinus may be a potential risk factor of vascular and dural injuries during surgical interventions $(6,17)$. By contrast, whether the different pneumatization of the CG and NS are associated with recurrent frontal sinusitis and may not have clinical symptoms remains unclear. The SCG can lead to pathologies, which include recurrent frontal sinusitis, mucocele and nasal dermoids. In addition, it may be a possible anatomical barrier during surgical resection of tumours localised in the anterior cranial fossa $(11,13,16,18)$. Using multiplanar reconstruction of CT scan images, the drainage pathway of the SCG and the positions of the $C G$ in relation to the cribriform plate can be described and this technique may play an important role in preventing recurrence and surgical complications $(4,8,13,16)$.

In 120 of 402 patients, the prevalence of the SCG was $29.8 \%$, which is similar to published studies with rates ranges from $2.4 \%$ to $37.5 \%(2,4,16,18)$. However, Mladina et al. and Odat and $\mathrm{Al}-\mathrm{Qudah}$ have found prevalence rates at $66.6 \%$ and $86 \%$, respectively, which are significantly higher than our results $(13,15)$. Via a subjective evaluation of the observer using human skulls in the study of Mladina et al., small pneumatized spaces surrounding the spongy bone were considered as SCG (13). Moreover, Odat and Al-Qudah have evaluated the paranasal sinus CT scan results of patients with sinonasal symptoms, which can increase the prevalence of pneumatization (15). In addition, we observed a drainage pathway through the frontal (57) and ethmoid (8) sinuses in 65 (54.2\%) of 120 (59 female, 61 male) patients (Table I). In addition, we observed that the SCG was a compartment of the FS in 8 of 57 patients. Poje et al. and Manea et al. have observed a connection to the FS in $12.1 \%$ and $16.98 \%$ of SCG, respectively $(10,16)$. In addition, no relationship was observed between the pneumatization patterns of the FS and the incidence of pneumatized CG in this study. We presented the results for the number of the SCG, which were as follows: bilateral and unilateral absence of the FS, $14(29.8 \%)$ of 47 ; bilateral presence of the FS, 88 (29.1\%) of 302 and triple FS, 18 (33.9\%) of 53 patients (Table $\mathrm{VI})$. Due to the limited comparative data in the literature, a comparison analysis cannot be performed.

Similar to the classification of Hajiioannou et al. (8), we categorised the localisation of the CG into three types based on the cribriform plate and found the following prevalence rates among the 402 patients: $18.3 \%(n=74)$ for type I, $64.9 \%$ ( $n=261)$ for type II and $16.8 \%(n=67)$ for type III. Compared with the outcomes of previous studies, ours showed minimal diversity based on the number of patients who were included, methodology and ethnicities as shown in Table $\mathrm{V}$ $(4,8,11,13,16)$. We analysed the incidence of pneumatization in these CG types, and the results were as follows: $37.8 \%$ $(28 / 74)$ in type I, 31.4\% (82/261) in type II and $14.9 \%(10 / 67)$ in type III (Table $\mathrm{VI})$. Thus, the SCG was mostly observed in types I and II $(p<0.05)$. Cobzeanu et al. have found that the prevalence of pneumatization was highest in type II (13.17\%), and type III was most commonly pneumatized (6.1\%) in the study of Hajiioannou et al. $(4,8)$. Mladina et al. have found type I in 31 SCG (45.58\%) and type II in 37 SCG (54.42\%), much higher than those in the present study (13).

When conservative treatment is not effective in cases of iatrogenic CSF leak, meningitis can develop, and surgical closure of the skull base defects with bone graft from the NS is required (17). Mladina et al. have indicated that the pneumatization of NS most commonly occurs from the sphenoid sinus or rarely from the FS and it has a considerable 
amount of pneumatization ranging from $26 \%$ to $32 \%$ (12). In this study, SSN was observed in 92 (50 female, 42 male) patients with a prevalence rate of $22.8 \%$ (Table I), which is slightly lower than that in previous studies $(2,12,20)$. By contrast, the SSN can be an individual sinus or a compartment of the adjacent paranasal sinuses via a drainage pathway and CG (12). Thus, we observed a communication with the sphenoid sinus in $15(16.3 \%)$ of 92 patients. However, the comparative data in the literature are limited.

The mean SCG and SSN volumes were $17.0 \pm 7.06$ and $12.9 \pm$ $7.05 \mathrm{~mm}^{3}$, respectively. Furthermore, the SCG volume showed a statistically significant difference between male and female (Table IV). In previous studies, the FS volume was measured using different radiologic methods. However, the SCG and SSN volumes were not analysed. Thus, a comparative analysis cannot be performed.

Different from other studies, which indicate each structure separately in the literature, we evaluated all bony structures in detail and analysed the relationship between them. The primary difference of this study was the measurement of SSN and SCG volumes, which were higher in male than female. The secondary advantage of the study include the fact that the drainage pathways of the SSN were assessed and the correlation between the pneumatization patterns of the FS and the incidence of SCG was reported.

The clinical role of the pneumatized CG and NS with respect to the pathogenesis of recurrent or asymptomatic paranasal sinusitis and benign neoplasms is debatable. The present study had few limitations. First, this retrospective study only evaluated asymptomatic patients. Although several studies have described pneumatization in patients with sinonasal symptoms and recurrent sinusitis, further studies that analyse the role of pneumatization in pathological conditions as well as postoperative outcomes and prognosis in surgical interventions must be carried out. Extensive investigations of control and patient groups, and pediatric age groups can provide researchers with more comprehensive results. Second, we analysed the lack of correlation between the pneumatization patterns of the FS and the incidence of SCG and compared the SCG and SSN volumes in terms of sex. Moreover, the drainage pathway of the SSN through the sphenoid sinus was assessed. However, the classification of CT scan results based on SCG volume, dehiscence of the bony structures and relationship with adjacent neurovascular structures were not assessed in this study. Thus, further studies must be conducted to address these issues.

\section{CONCLUSION}

Based on the CT scan results, a considerable amount of pneumatization was observed in the extrasinusal ethmoid structures (29.8\% in the SCG and $22.8 \%$ in the SSN). In addition, the drainage pathways of the SCG and SSN can be easily detected on CT scan. The prevalence of type II CG was the highest, and SCG was commonly observed in types I and II. The results of our study can further increase the knowledge of a surgeon about the normal anatomy of these bony structures, which is essential in anterior skull base surgery or ESS. For a safer and more effective surgery and the prevention of iatrogenic complications, a surgeon should be aware of these anatomical variations.

\section{REFERENCES}

1. Akhlaghi M, Bakhtavar K, Moarefdoost J, Kamali A, Rafeifar $S$ : Frontal sinus parameters in computed tomography and sex determination. Leg Med (Tokyo) 19:22-27, 2016

2. Al-Qudah M: Anatomical variations in sino-nasal region: $A C T$ study. J Med J 44:290-297, 2010

3. Caylakli F, Cagici AC, Yilmazer C, Ozer F, Ozluoglu L: Hyperaeration of the frontal sinus. Auris, Nasus, Larynx 33:471-473, 2006

4. Cobzeanu MD, Baldea V, Baldea MC, Vonica PS, Cobzeanu BM: The anatomo-radiological study of unusual extrasinusal pneumatizations: Superior and supreme turbinate, crista galli process, uncinate process. Rom J Morphol Embryol 55:10991104, 2014

5. Danesh-Sani SA, Bavandi R, Esmaili M: Frontal sinus agenesis using computed tomography. J Craniofac Surg 22:e48-51, 2011

6. Flanigan P, Kshettry VR, Mullin JP, Jahangiri A, Recinos PF: Frontal sinus morphometry in relation to surgically relevant landmarks in the United States population. World Neurosurg 91:12-15, 2016

7. Gotlib T, Kuzminska M, Held-Ziolkowska M, OsuchWojcikiewicz E, Niemczyk K: Hidden unilateral aplasia of the frontal sinus: A radioanatomic study. Int Forum Allergy Rhinol 5:441-444, 2015

8. Hajiioannou J, Owens D, Whittet HB: Evaluation of anatomical variation of the crista galli using computed tomography. Clin Anat 23:370-373, 2010

9. Kim JJ, Cho JH, Choi JW, Lim HW, Song YJ, Choi SJ: Morphologic analysis of crista galli using computed tomography. J Rhinol 19:91-99, 2012

10. Manea C, Mladina R: Crista galli sinusitis - a radiological impression or a real clinical entity. J Rhinol 6:167-171, 2016

11. Min HJ, Kim KS: Frontal headache caused by infection of pneumatized crista galli. J Craniofac Surg 27:352-354, 2016

12. Mladina R, Antunović R, Cingi C, Bayar Muluk N, Skitarelić $\mathrm{N}$ : Sinus septi nasi: Anatomical study. Clin Anat 30:312-317, 2017

13. Mladina R, Antunovic R, Cingi C, Muluk NB, Skitarelic N, Malic $\mathrm{M}$ : An anatomical study of pneumatized crista galli. Neurosurg Rev 40:671-678, 2017

14. Nikam SS, Gadgil RM, Bhoosreddy AR, Shah KR, Shirsekar VU: Personal identification in forensic science using uniqueness of radiographic image of frontal sinus. J Forensic Odontostomatol 33:1-7, 2015

15. Odat $\mathrm{H}, \mathrm{Al}-\mathrm{Qudah} \mathrm{M}$ : Concha bullosa and ethmoid structures pneumatization: The effect of altitude and other variables. J Craniofac Surg 27:667-669, 2016

16. Poje G, Mladina R, Skitarelic N, Kavanagh MM: Some radiological and clinical aspects of the sinus crista galli. Romanian Journal of Rhinology 4:31-36, 2014 
17. Prosser JD, Vender JR, Solares CA: Traumatic cerebrospinal fluid leaks. Otolaryngol Clin North Am 44:857-873, vii, 2011

18. Som PM, Park EE, Naidich TP, Lawson W: Crista galli pneumatization is an extension of the adjacent frontal sinuses. AJNR Am J Neuroradiol 30:31-33, 2009

19. Soman BA, Sujatha GP, Lingappa A: Morphometric evaluation of the frontal sinus in relation to age and gender in subjects residing in Davangere, Karnataka. J Forensic Dent Sci 8:57, 2016

20. Stoyanov G, Moneva K, Sapundzhiev N, Tonchev AB: The vomeronasal organ - incidence in a Bulgarian population. J Laryngol Otol 130:344-347, 2016

21. Tatlisumak E, Ovali GY, Asirdizer M, Aslan A, Ozyurt B, Bayindir P, Tarhan S: CT study on morphometry of frontal sinus. Clin Anat 21:287-293, 2008
22. Tezer MS, Tahamiler R, Canakcioglu S: Computed tomography findings in chronic rhinosinusitis patients with and without allergy. Asian Pac J Allergy Immunol 24:123-127, 2006

23. Vazquez A, Baredes S, Setzen M, Eloy JA: Overview of frontal sinus pathology and management. Otolaryngol Clin North Am 49:899-910, 2016

24. Yu JL, Branstetter BF $4^{\text {th }}$, Snyderman $\mathrm{CH}$ : Frontal sinus volume predicts incidence of brain contusion in patients with head trauma. J Trauma Acute Care Surg 76:488-492, 2014

25. Yuksel Aslier NG, Karabay N, Zeybek G, Keskinoglu P, Kiray A, Sutay S, Ecevit MC: The classification of frontal sinus pneumatization patterns by CT-based volumetry. Surg Radiol Anat 38:923-930, 2016 